\title{
Histological evaluation of direct pulp capping with all-in-one adhesives in rat teeth
}

\author{
Koichi SHINKAI, Yoshihisa TAIRA, Satoki KAWASHIMA, Shiro SUZUKI and Masaya SUZUKI \\ Department of Operative Dentistry, The Nippon Dental University School of Life Dentistry at Niigata, 1-8 Hamaura-cho, Niigata 951-8580, Japan \\ Corresponding author, Koichi SHINKAl; E-mail: shinkaik@ngt.ndu.ac.jp
}

\begin{abstract}
The aim of this study was to histologically evaluate direct pulp capping using different all-in-one adhesives in rat teeth. Five allin-one adhesives and a control material (MTA) were used. Each material was applied on the exposed pulp, and each cavity was subsequently restored with the resin composite. Rats were sacrificed 14 days after the surgical procedure. Serial stained sections were histologically evaluated for examining pulp tissue disorganization (PTD), inflammatory cell infiltration (ICI), dentin bridge formation (DBF), and bacterial penetration (BP). We found that rat pulps, which were direct capped with all-in-one adhesives, showed various degrees of PTD, ICI, and DBF depending on the material, and that there were no complete dentin bridges. In contrast, rat pulps capped with MTA showed no PTD and ICI, and there were complete dentin bridges in all, but one specimen. No $\mathrm{BP}$ was observed in any specimen.
\end{abstract}

Keywords: Histological evaluation, Direct pulp capping, All-in-one adhesive, Rat pulp, Biocompatibility

\section{INTRODUCTION}

In case of deep dental caries treatment, indirect pulp capping procedure including selective or stepwise removal of deep caries $^{1)}$ has frequently been applied to avoid exposing dental pulp. Although indirect pulp capping is a secure treatment for dental pulp, its operating procedure is complicated and requires long period to achieve the task. These disadvantages are undesirable for both patient and clinician. When treating a deep caries, one day treatment with resin composite restoration could be preferred for clinicians. If an accidental pulp exposure occurred during removing dental caries, direct pulp capping is generally applied using various materials.

Direct pulp capping with adhesive resin composites could reportedly be acceptable for clinical use, according to the results of various animal studies ${ }^{2-8)}$. Cox et $a l^{3,5)}$ revealed that bacterial microleakage around a resin composite restoration was responsible for pulpal inflammation rather than the resin composite compositions including those of the adhesives. Our previous study also revealed that self-etch adhesive systems were harmless for exposed primate dental pulp despite delaying the dentin bridge formation $(\mathrm{DBF})^{8)}$.

On the other hand, several in vitro studies have reported regarding the cytotoxic effects of unpolymerized components of adhesive resins on fibroblasts and odontoblast-like cells ${ }^{9-14)}$. Furthermore, the results observed among animal studies concerning direct pulp capping with adhesive systems appeared to be different from those observed among studies utilizing similar methods in human teeth ${ }^{15}$. Thus, the effects of adhesive resins on the direct pulp capping procedure have been

Color figures can be viewed in the online issue, which is available at J-STAGE.

Received Apr 21, 2016: Accepted Nov 7, 2016

doi:10.4012/dmj.2016-148 JOI JST.JSTAGE/dmj/2016-148 controversial.

Recently, an all-in-one adhesive (one-step selfetching adhesive) system has been developed, and several all-in-one adhesives are used in clinics. Because the clinical application of all-in-one adhesives is easy, this type of adhesive may be advantageous in direct pulp capping compared with other adhesives, which require multiple steps for bonding. Although a low dentin bond strength has been reported in several studies for the early all-in-one adhesives compared with the conventional two-step self-etching adhesives ${ }^{16,17)}$, the latest all-inone adhesives have shown an improvement in dentin bonding efficacy, which is equivalent to two-step selfetching adhesives ${ }^{18,19)}$. However, several studies have reported that the enamel bond strength of self-etching adhesive systems, including both one-step and two-step systems, was still insufficient compared with that of etch and rinse adhesive systems ${ }^{20-25}$. This insufficiency may lead to microleakage at the tooth-resin interface.

An all-in-one adhesive may be a candidate for direct pulp capping because of its ease of handling; however, the effects of its disadvantages, such as complex compositions and insufficient enamel bond strength, on direct pulp capping have not yet been demonstrated. The study aimed to histologically evaluate direct pulp capping using all-in-one adhesives in rat teeth. This study investigated the rat pulp response to direct pulp capping using all-in-one adhesives compared with that using mineral trioxide aggregate cement (MTA, Pro Root MTA, Dentsply Tulsa Dental, Johnson City, TN, USA) as a control.

\section{MATERIALS AND METHODS}

Experimental animals

A total of 30 non-carious teeth (upper first molars) from 
15 rats (Sprague-Dawley male rats; 8-9 weeks old; and approximately 300-400 g in weight) were treated with direct pulp capping. Five teeth were assigned to each experimental group. This study was approved by the Laboratory Animal Committee of The Nippon Dental University School of Life Dentistry at Niigata (receipt and permission number: 126).

\section{Specimen preparation}

The rats were sedated with ether (diethyl ether, Wako Pure Chemical Industries, Osaka, Japan), and general anesthesia was subsequently achieved by an intraperitoneal injection of a medetomidine (Domitor ${ }^{\mathbb{R}}$, Nippon Zenyaku Kogyo, Fukushima, Japan), midazolam (Sandoz ${ }^{\circledR}$, Sandoz, Tokyo, Japan), and butorphanol (Domitor $^{\circledR}$, Meiji Seika Pharma, Tokyo, Japan) mixture at a dose of $0.15,2.0$, and $2.5 \mathrm{mg} / \mathrm{kg}$ (body weight/rat), respectively. Each rat was fixed on an operating board, and the mouth was kept in an open position using a jaw prop. The teeth were cleaned using 3\% hydrogen peroxide $\left(\mathrm{Oxydol}^{\circledR}\right.$, Yoshida Pharmaceutical, Tokyo, Japan), rinsed using physiological saline (Physisalz ${ }^{\circledR}$ PL-D, Fuso Pharmaceutical Industries, Osaka, Japan), and disinfected using diluted iodine tincture (Yoshida Pharmaceutical).

Bowl-shaped cavities with a diameter of approximately $0.5 \mathrm{~mm}$ were prepared on the mesial marginal ridge of the right and left maxillary first molars using an FG \#440SS regular-cut diamond point (Shofu, Kyoto, Japan) in a high-speed hand piece (Air-turbine hand piece, Super Load 9000, Yoshida, Tokyo, Japan) under a water coolant. The pulps were subsequently carefully exposed using a CA\#1/2 steel round bur (Hager $\&$ Meisinger, Neuss, Germany) in a low-speed hand piece (Micromotor hand piece, Micro-Mega, Yoshida) under a distilled water coolant without penetrating into the pulp space. Hemorrhage from the exposed pulp was stopped with the application of $10 \%$ sodium hypochlorite $(\mathrm{NaOCl})$ gel (AD Gel, Kuraray Noritake Dental, Tokyo, Japan) for $5 \mathrm{~min}$. The $\mathrm{AD}$ gel was reapplied if hemorrhage continued. Alternate irrigations using $3 \% \mathrm{H}_{2} \mathrm{O}_{2}$ and $6 \%$ $\mathrm{NaOCl}$ solution (Purelox, Oyalox, Tokyo, Japan) were performed thrice to remove the $\mathrm{AD}$ gel and dentin chips followed by rinsing with physiological saline. The excess water was removed using sterilized, small cotton pellets, and the cavity was gently air-blown to dry.

Each all-in-one adhesive (Table 1) was applied to the cavities, according to each manufacturer's instruction, to achieve direct pulp capping. The teeth capped with MTA were used as a control group. After the direct capping procedures, all cavities were filled with a hybrid resin composite (Clearfil Majesty A3, Kuraray Noritake Dental) and photo-polymerized using a curing light (Candelux, Morita, Tokyo, Japan) for $40 \mathrm{~s}$.

\section{Perfusion fixation and tissue preparation}

The rats were sacrificed with an intraperitoneal overdose injection of the general anesthetic solution mentioned above after an observation period of 14 days. Each pulp was fixed through transcardial perfusion with a $4 \%$ paraformaldehyde phosphate buffer solution $(\mathrm{pH}$ 7.4; Wako Pure Chemical Industries). The maxillary bone specimens containing the experimental teeth were carefully removed and immersed in the same fixative at $4^{\circ} \mathrm{C}$ for an additional $24 \mathrm{~h}$. After fixation, the specimens were trimmed of excess tissue and decalcified using $10 \%$ EDTA-2Na solution ( $\mathrm{pH}$ 7.4) at room temperature for 4 weeks; next, the filled material was carefully removed from the cavity and rinsed with running water for 24 $\mathrm{h}$. The specimens were subsequently dehydrated in increasing concentrations of ethanol, dealcoholized with xylene, and finally embedded in paraffin.

Table 1 Composition of the materials used in this study

\begin{tabular}{|c|c|c|c|c|}
\hline Material & Abbrev. & Lot \# & Composition & Manufacturer \\
\hline $\begin{array}{l}\text { Clearfil Tri-S } \\
\text { Bond ND }\end{array}$ & CTB & 00009A & $\begin{array}{l}\text { Bis-GMA, MDP, HEMA, Photoinitiators, } \\
\text { Ethanol, Water, Silanated colloidal silica, CQ }\end{array}$ & $\begin{array}{l}\text { Kuraray Noritake } \\
\text { Dental }\end{array}$ \\
\hline G Bond Plus & GBP & 1009101 & $\begin{array}{l}\text { Phosphonic acid monomer, 4-MET, Dimethacrylate, } \\
\text { Acetone, Water, Nano silica filler, Initiator, CQ }\end{array}$ & GC \\
\hline Bond Force & $\mathrm{BF}$ & 086 & $\begin{array}{l}\text { Phosphoric acid monomer, Bis-GMA, HEMA, } \\
\text { TEGDMA, Alcohol, Water, CQ }\end{array}$ & Tokuyama Dental \\
\hline $\begin{array}{l}\text { Adper Easy } \\
\text { Bond }\end{array}$ & AEB & 407565 & $\begin{array}{l}\text { HEMA, Bis-GMA, Methacrylated phosphoric esters, } \\
\text { 1,6 Hexanediol dimethacrylate, Polyalkenoic acid, } \\
\text { Silica filler, Ethanol, Water, Stabilizers, CQ }\end{array}$ & 3M ESPE Dental \\
\hline Xeno V & $\mathrm{XV}$ & 1005001356 & $\begin{array}{l}\text { Bifunctional acrylic amides, Acryloamido } \\
\text { alcylsulfonic acid, Functionalized phosphoric acid } \\
\text { ester, Acrylic acid, Butylated benzenediol, } \\
\text { Water, Tertiary butanol, Initiators, CQ }\end{array}$ & Dentsply Sankin \\
\hline Pro root MTA & MTA & 09003850 & $\mathrm{CaO}, \mathrm{SiO}_{2}, \mathrm{Al}_{2} \mathrm{O}_{3}, \mathrm{Fe}_{2} \mathrm{O}_{3}, \mathrm{Bi}_{2} \mathrm{O}_{3}, \mathrm{CaSO}_{4} \cdot 2 \mathrm{H}_{2} \mathrm{O}$ & Dentsply Tulsa Dental \\
\hline
\end{tabular}




\section{Serial sectioning and staining}

Serial sections of $6 \mu \mathrm{m}$ thick were longitudinally cut through the center of each tooth using a sliding microtome (Jung Histoslide 2000R, Leica Microsystems Vertrieb, Wetzlar, Germany) and stained using Mayer's hematoxylin-eosin (HE) staining, modified NF-Watanabe's (NF) silver impregnation staining, and Hucker-Conn (HC) bacterial staining methods. DMP1 staining method was used for immunohistochemical evaluations.

\section{Observation items and evaluation criteria}

The stained sections were observed under a light microscope (Eclipse E1000; Nikon, Tokyo, Japan). Four histological features, such as pulp tissue disorganization (PTD), inflammatory cell infiltration (ICI), dentin bridge formation (DBF), and bacterial penetration (BP), were evaluated, according to the criteria listed in Table 2. Two observers determined the score of each specimen; in cases of disagreement between the two observers, a third observer participated to determine the score.

\section{Measurement of the diameter of exposed pulp area}

The diameter of the exposed area was measured using a stereomicroscope (Measuring Microscope MM-40, Nikon), and the widest dimension was recorded as the size of the pulp exposure for the specimen.

\section{Statistical analysis}

The exposure size data were analyzed using the one-way analysis of variance and Tukey's post hoc test. Results of the histopathological evaluation were statistically analyzed using the Kruskal-Wallis test to determine the differences between the experimental groups. Statistical procedures were performed at a significance level of 0.05 using the statistical software (Microsoft Excel 2010 for windows, SSRI, Tokyo Japan).

We wished to establish the smallest number of rats scarified in this study, because of the spirits of animal protection. We calculated the power of the KruskalWallis H-test at an effect size of 0.5 (Cohen's large effect size), alfa error probability of 0.05 , total sample size of 30, and number of groups of 6 using Power analysis software (G Power 3.0.1.0). As the results, the power of the Kruskal-Wallis H-test performed in this study was 0.43 .

\section{RESULTS}

\section{Diameter of exposed pulp area}

The diameter (mean \pm SD) of the exposed pulp area in each group ranged from $0.197 \pm 0.043$ to $0.303 \pm 0.077$ $\mathrm{mm}$. There were no significant differences between the groups in the pulp exposure size $(p=0.080)$.

\section{Histopathological evaluation (statistical assessment)}

Figure 1 presents a summary of the results of the histopathological evaluation. Representative histopathological images of the materials are shown in Figs. 2-7. The results of the Kruskal-Wallis test for

Table 2 Evaluation criteria for each observation item

\begin{tabular}{|c|c|}
\hline \multicolumn{2}{|c|}{ Pulp tissue disorganization } \\
\hline None & Normal or almost normal tissue morphology \\
\hline Mild & Odontoblast layer disorganization, but the deep part of the pulp appears normal \\
\hline Moderate & Loss of general tissue morphology \\
\hline Severe & Necrosis in the coronal one-third or more of the pulp \\
\hline \multicolumn{2}{|c|}{ Inflammatory cell infiltration } \\
\hline None & Absence or presence of a few scattered inflammatory cells in the pulp \\
\hline Mild & Mild acute/chronic cell lesions \\
\hline Moderate & $\begin{array}{l}\text { Moderate inflammatory cell lesions seen as abscesses or densely stained infiltrates of polymorphonuclear } \\
\text { leucocytes, histiocytes, and lymphocytes in one-third or more of the coronal pulp and/or the mid-pulp }\end{array}$ \\
\hline Severe & Pulp necrosis due to severe degree of infection or lack of tissue in one-half or more of the pulp \\
\hline \multicolumn{2}{|c|}{ Reparative dentin formation } \\
\hline None & No dentin bridge formation \\
\hline Initial & Initial dentin bridge formation extending to not more than one-half of the exposure site \\
\hline Partial & $\begin{array}{l}\text { Partial/incomplete dentin bridge formation extending to more than one-half of the exposure site but not } \\
\text { completely closing the exposure site }\end{array}$ \\
\hline Complete & Complete dentin bridge formation \\
\hline \multicolumn{2}{|c|}{ Bacterial penetration } \\
\hline None & Absence of stained bacterial profiles in any parts of the sections \\
\hline Mild & Presence of stained bacterial profiles along the coronal or apical walls of the cavity \\
\hline Moderate & Presence of stained bacterial profiles within the cut dentinal tubules or axial walls of the cavity \\
\hline Severe & Presence of stained bacterial profiles within the dental pulp \\
\hline
\end{tabular}




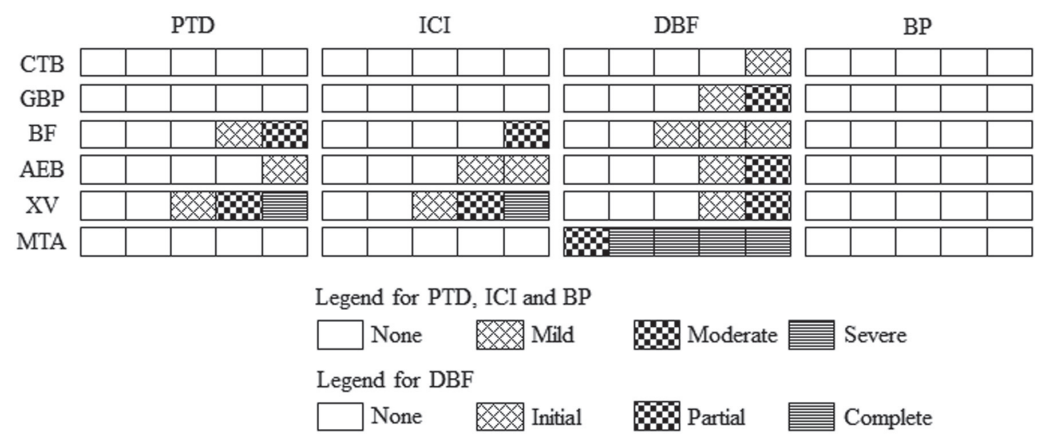

Fig. 1 Summary of the results of the histopathological evaluation.

Pulp tissue disorganization (PTD), Inflammatory cell infiltration (ICI), Dentin bridge formation (DBF), Bacterial penetration (BP).
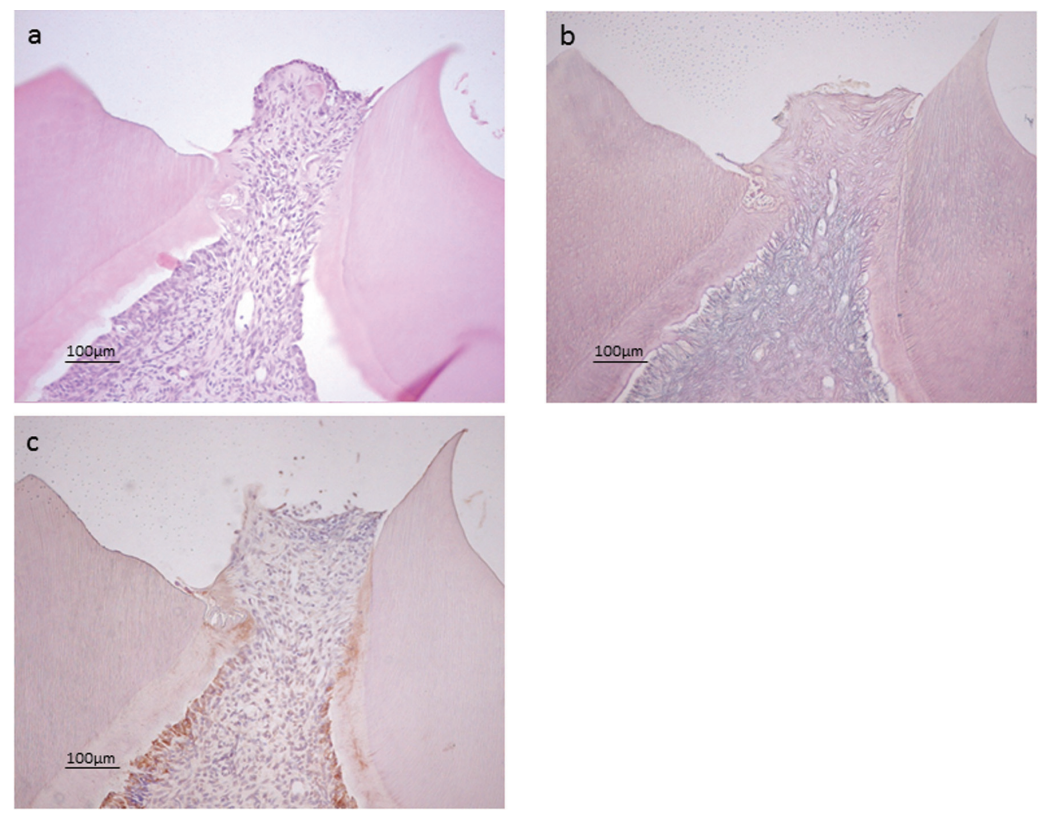

Fig. 2 Representative histologic images of CTB $(\times 100)$.

(a) H-E staining, (b) NF staining, (c) DMP1 staining. Mild PTD and no ICI were observed at the exposure site, but the surface of the exposed pulp was not covered by hard tissue. Reticular collagenous fibers were observed at the exposed pulp surface.

the histopathological evaluation showed no significant differences among all materials for PTD parameter $(p=0.072)$ and ICI parameter $(p=0.082)$, and among the five adhesive materials (CTB, GBP, BF, AEB, and $\mathrm{XV})$ for the DBF parameter $(p=0.858)$. In contrast, the results of the Kruskal-Wallis test showed significant differences among all materials for the DBF parameter $(p=0.014)$, and Steel post-hoc test showed significant differences between MTA and each adhesive material $(p<0.05)$.

\section{PTD and ICI findings}

Normal pulpal tissue morphology was observed in all specimens capped with CTB, GBP, and MTA, whereas mild to moderate PTD and ICI were observed in some specimens capped with $\mathrm{BF}, \mathrm{AEB}$, and $\mathrm{XV}$ at 14 days postoperatively. Severe PTD and ICI were observed in one XV specimen. As shown in Figs. 2 (the specimen capped with CTB) and 5 (the specimen capped with AEB), mild PTD and no ICI were observed at the exposure site, but the surface of the exposed pulp was not covered by hard tissue. 

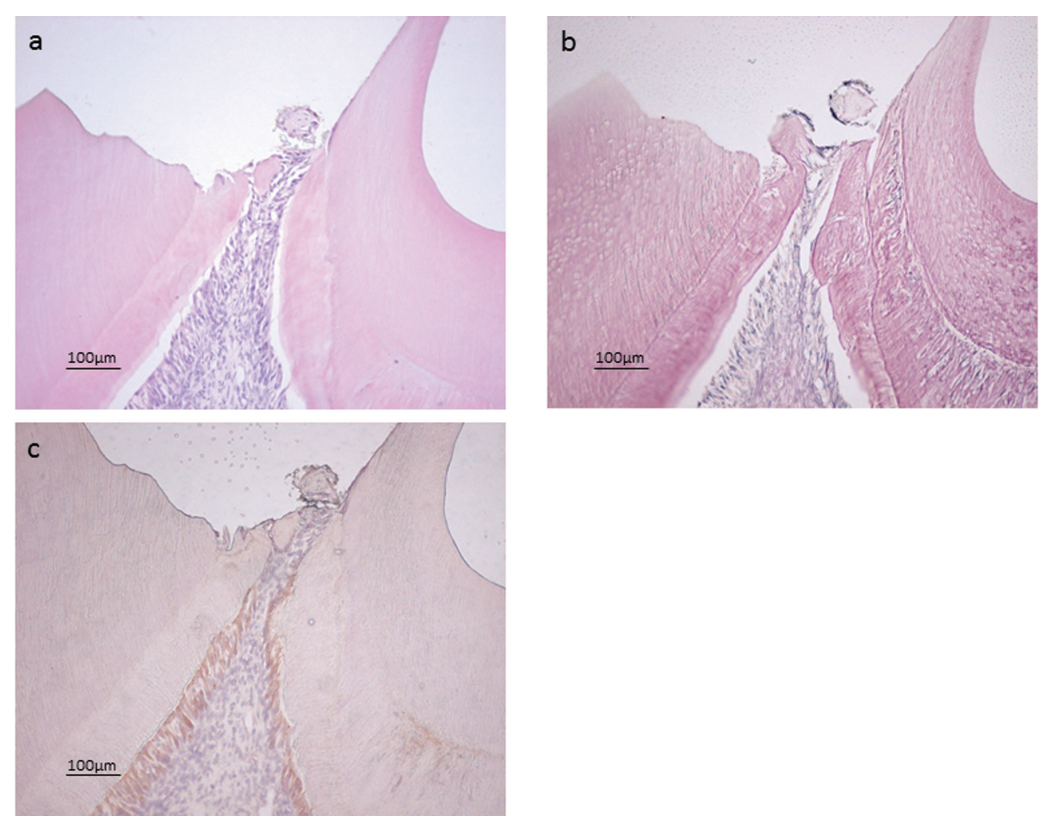

Fig. 3 Representative histologic images of GBP $(\times 100)$.

(a) H-E staining, (b) NF staining, (c) DMP1 staining. An initial DBF was observed at the exposed pulp surface.
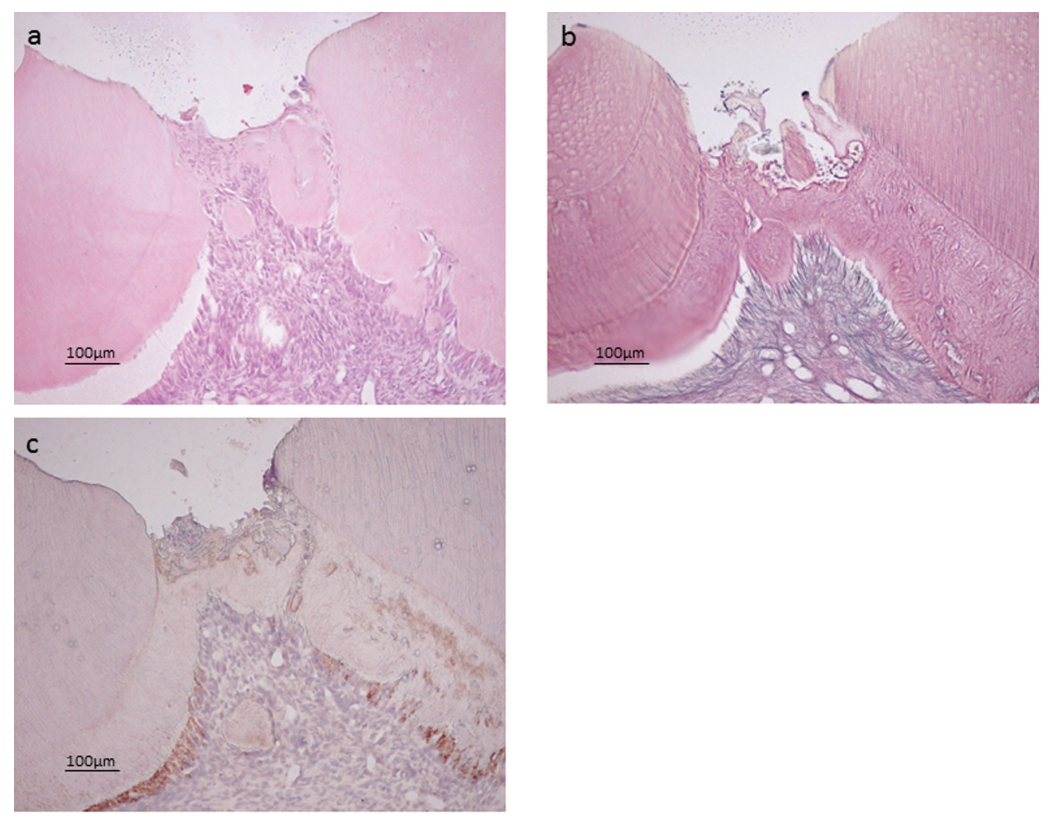

Fig. 4 Representative histologic images of BF $(\times 100)$.

(a) H-E staining, (b) NF staining, (c) DMP1 staining. A partial DBF was observed at the exposed pulp surface.

\section{DBF findings}

Four of the five specimens in the control group (capped with MTA) showed a complete DBF; the remaining one specimen showed an incomplete DBF. In contrast, all specimens in the all-in-one adhesive groups showed an incomplete DBF; however, some specimens showed some initial to partial DBF. As shown in Fig. 3 (the specimen capped with GBP), an initial DBF was observed at the 

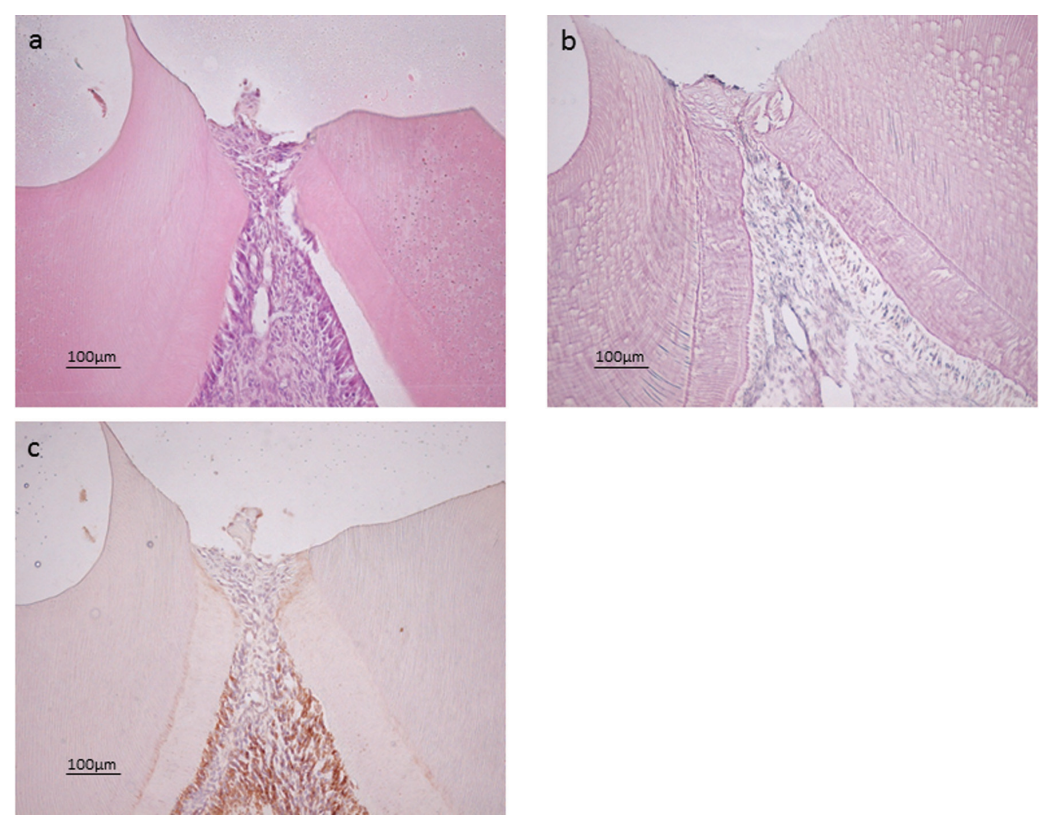

Fig. 5 Representative histologic images of AEB $(\times 100)$.

(a) H-E staining, (b) NF staining, (c) DMP1 staining. The surface of the exposed pulp was not covered by hard tissue.
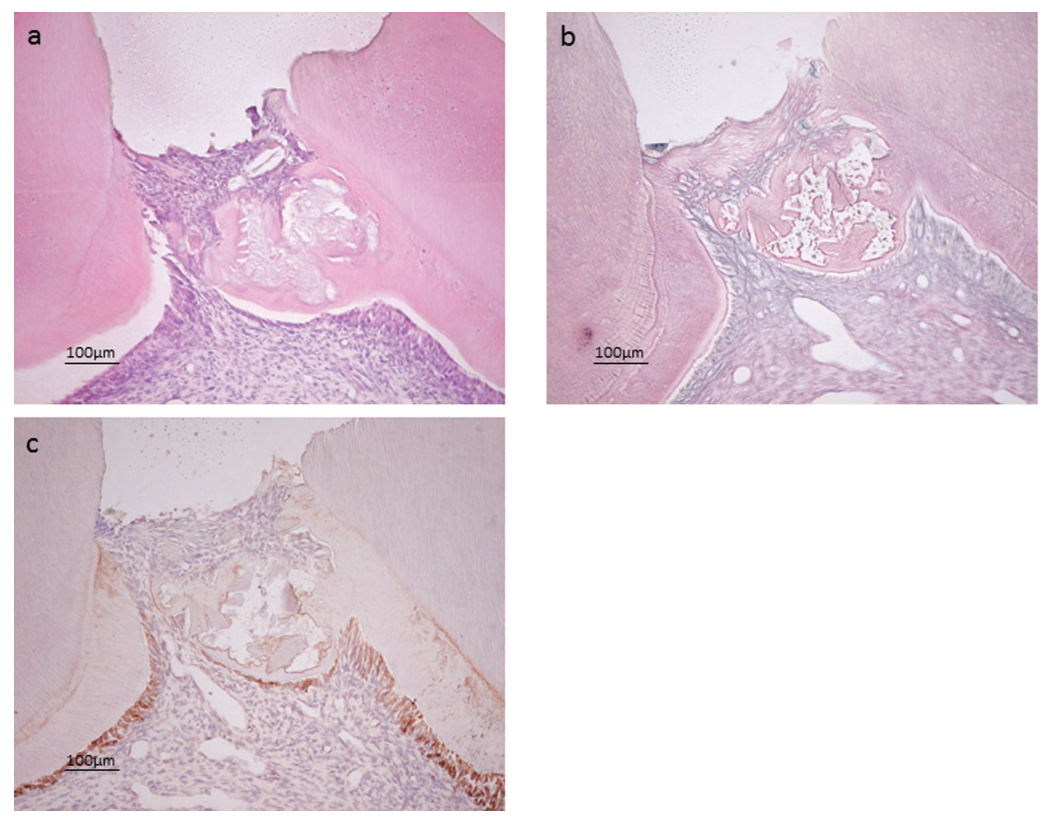

Fig. 6 Representative histologic images of XV $(\times 100)$.

(a) H-E staining, (b) NF staining, (c) DMP1 staining. There was an incomplete DBF at a comparatively deeper position from the pulpal exposed site. Reticular collagenous fibers were observed at the exposed pulp surface.

exposed pulp surface. A partial DBF was observed at the exposed pulp surface in the specimens capped with $\mathrm{BF}$ (Fig. 4) and those capped with XV (Fig. 6).

\section{BP findings}

At 14 days postoperatively, none of the specimens stained positively for bacteria. 

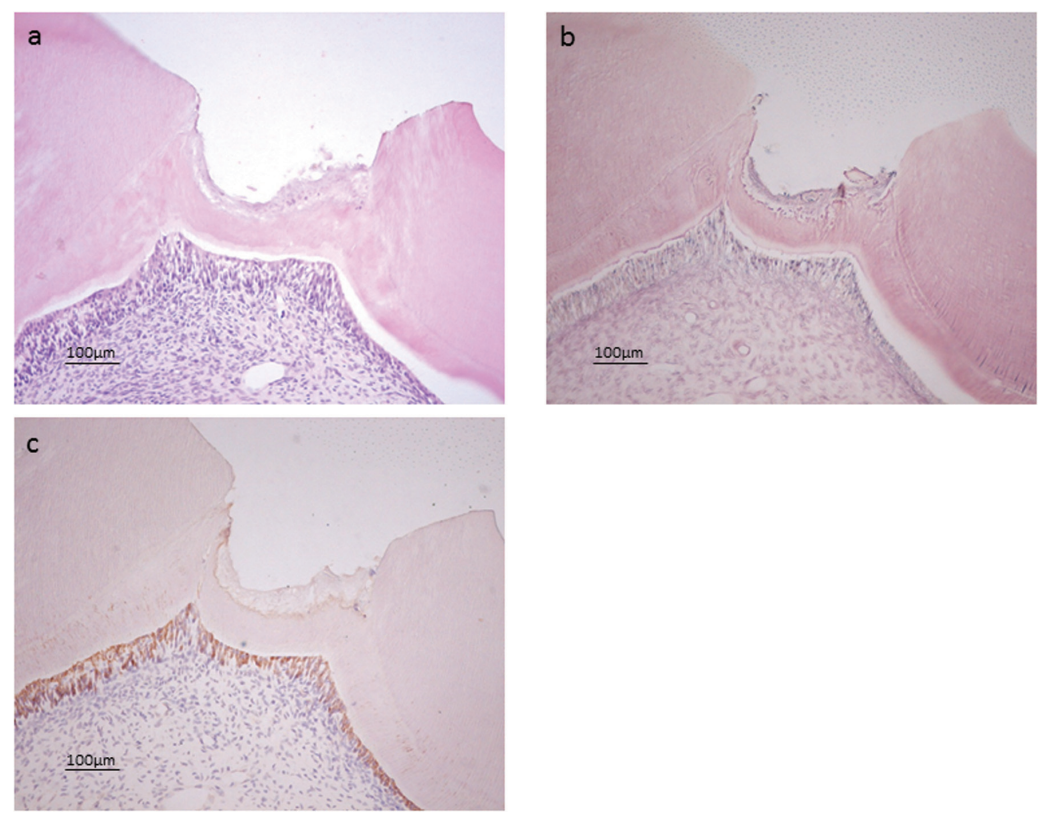

Fig. 7 Representative histologic images of MTA $(\times 100)$. (a) H-E staining, (b) NF staining, (c) DMP1 staining. Complete DBF was observed at the exposed pulp surface.

\section{DISCUSSION}

The results of statistical analysis for the histopathological evaluation showed no significant differences among all materials for PTD and ICI parameters $(p>0.05)$. However, those for PTD and ICI parameters showed a tendency of dependence on the materials. No PTD and ICI was observed in the specimens capped with CTB, GBP or MTA; however, BF, AEB and XV showed mild to severe PTD and ICI. This discrepancy may be due to the differences in the chemical composition of the adhesives. Some adhesive components might chemically irritate the dental pulp and cause inflammatory cell invasions beneath the exposed pulp surface. A previous study, which had evaluated the cytotoxic effects of conventional and resin-modified glass-ionomer cements on an odontoblast cell line (MDPC-23), showed that the conventional types were the least cytotoxic, whereas the resin-modified types were the most cytopathic ${ }^{26)}$. Furthermore, the authors suggested that unreacted HEMA significantly contributes to the cytotoxicity of the resin-modified types used in pulp cell cultures. Becher et $a{ }^{133}$ reported that TEGDMA was more cytotoxic than HEMA; HEMA caused a larger accumulation of apoptotic cells using the MTT assay and fluorescence microscopy. Kurata et al. ${ }^{27)}$ reported that the fibroblast growth after exposure to acrylic acid decreased with an increase in acid concentration and was lesser than that after exposure to methacrylic acid. Thus, the cytotoxicity of these chemical components has been recognized in many studies, and the cytotoxic effects varied among the studies. The inflammatory changes that remained after 14 days in the three XV specimens might have been caused by chemical irritation from the acrylic acid contained in the components. Those in the one $\mathrm{BF}$ specimen and two AEB specimens might have been caused by chemical irritation from the HEMA or TEGDMA; however, all specimens capped with CTB showed no inflammatory changes in spite of containing HEMA. Thus, from the results of this study, the correlation between chemical composition of adhesives and dental pulp irritation remained unclear. The permeability of the adhesive monomers into pulp tissue and the polymerization degree of the adhesives might also correlate to the irritation of the pulp tissue ${ }^{15)}$.

In the direct pulp capping treatment, bacterial microleakage has been identified as an important factor for pulpal irritation. Several studies have described that the response of the dentin-pulp complex does not depend on the dental materials used for pulp capping, but on their ability to prevent bacterial microleakage ${ }^{2-8)}$. Our previous study revealed that some of the self-etching adhesives induced moderate to severe inflammatory pulp responses with positive bacterial staining ${ }^{8}$. Cui et al. ${ }^{14)}$ also reported that most specimens with positive bacterial staining showed diverse pulpal responses. Scarano et al. ${ }^{28)}$ emphasized that bacterial microleakage critically affected pulpal repair and that the direct pulp capping with a self-etch adhesive system did not damage the dental pulp. Conversely, Silva et al. ${ }^{29)}$ reported that pulp necrosis occurred in all specimens capped with Adper Prompt even without bacterial staining, and 
they speculated that this pulp necrosis was primarily induced by the adhesive chemical component toxicity to the exposed pulp tissue. The results of the present study showed negative bacterial staining for all specimens, whereas some specimens capped with an all-in-one adhesive exhibited mild to severe PTD or ICI after 14 days. We speculate that some components contained in the all-in-one adhesives might chemically irritate the dental pulp. This might have caused the pulpal responses that remained after 14 days.

The slow DBF with all-in-one adhesives used in this study corresponded to that of a two-step self-etch adhesive system, which was investigated in our previous studies and other studies ${ }^{5-8}$. Some specimens with all-inone adhesives exhibited an initial to partial DBF after 14 days, whereas the MTA controls formed complete DBFs in five of the six specimens. Furthermore, several studies found that the adhesive systems used for direct pulp capping exhibited incomplete $\mathrm{DBF}$ with varying degrees of mineralization, and none of the adhesive systems exhibited complete $\mathrm{DBF}^{5,29,30)}$. Costa et al. speculated that some resin components were toxic to exposed pulp over a short period and that the resin components released into the pulp may delay pulpal healing ${ }^{311}$.

Several investigations have shown that non-human dental pulps capped with adhesives exhibited a slight initial inflammatory reaction; however, pulp repair with DBF was observed even after the short-term evaluation period $^{6,732)}$. A previous study involving human teeth reported that the histological reactions of the exposed dental pulp to total-etch and self-etch systems were generally comparable to those to calcium hydroxide after 15 days, and active odontoblasts were observed at the periphery of the exposed pulp beneath the composite resins in all specimens ${ }^{299}$.

As shown in Figs. 2-6, the positive staining of DMP1 at the odontoblastic layer indicated the reparative dentin formation in the present study. Therefore, it will be necessary to investigate the long-term pulpal responses to direct pulp capping with self-etch adhesive systems in a future study.

From the results of this study, MTA controls demonstrated excellent efficacy for hard tissue formation, as shown in several previous studies ${ }^{33-35}$. Min et $a l .{ }^{33)}$ reported that MTA was superior to calcium hydroxide in terms of DBF during the early wound healing process and that the superiority of MTA was associated with the expression of a cytoprotective molecule, hemeoxygenase (HO)-1, in human dental pulp. Kuratate et $a l .{ }^{34)}$ clarified that the reparative process in exposed pulps after the use of MTA involved the initial deposition of osteopontin in the superficial pulpal tissue followed by the appearance of newly-differentiated nestin-immunoreactive odontoblast-like cells. In our study, the odontoblasts beneath the dentin bridge formed by the MTA application showed positive staining for DMP1. This finding also supported the speculation that DBF in response to MTA involved the proliferation of stem cells, their migration into the exposed pulp surface, and their differentiation into odontoblast-like cells.
Furthermore, it has been reported that MTA induced dose-dependent contractions in the rat thoracic aorta; this property of MTA may allow appropriate control of hemorrhage, which is important in the success of direct pulp capping ${ }^{35}$.

In our study of a series of direct pulp capping procedures, we applied the $\mathrm{AD}$ gel $(10 \% \mathrm{NaOCl}$ gel $)$ to the exposed pulp surface to control hemorrhage, following three alternating irrigations using both $3 \%$ $\mathrm{H}_{2} \mathrm{O}_{2}$ and $6 \% \mathrm{NaOCl}$ solutions to remove the $\mathrm{AD}$ gel and dentin chips. Some studies have reported that the application of $\mathrm{NaOCl}$ to exposed pulp surface is an important procedure ${ }^{4,5)}$ because this solution can control infection and hemorrhage and prevent blood clot formation. On the other hand, several studies have demonstrated the cytotoxicity of $\mathrm{NaOCl}$ even at low concentrations. Costa et al. ${ }^{36)}$ demonstrated that $0.12 \%$ $\mathrm{NaOCl}$ was toxic to a cultured odontoblast cell line (MDPC-23). Heggers et al. ${ }^{37}$ ) has reported that $0.025 \%$ $\mathrm{NaOCl}$ solution is therapeutically effective because it retains its bactericidal properties and eliminates any harmful impacts on wound healing. For these reasons, some researchers have controlled hemorrhage using sterile water instead of $\mathrm{NaOCl}$ solution. Based on our experience during animal studies, it is very difficult to stop bleeding using only sterile water irrigation; however, application of $10 \% \mathrm{NaOCl}$ gel on the exposed pulp is very effective. Although, $10 \%$ of $\mathrm{NaOCl}$ gel is a very high concentration its cytotoxic effect may be limited on the superficial pulp tissues because of its low viscosity. Our previous studies had not demonstrated any harm from the direct application of $10 \% \mathrm{NaOCl}$ gel on the exposed dental pulp. Therefore, we used 10\% $\mathrm{NaOCl}$ gel for controlling hemorrhage from exposed pulp tissue in our present study. We also experienced that re-bleeding from exposed pulp occurred after the self-etching primer application to the cavity for direct pulp capping using two-step self-etching adhesives. However, in the present study, re-bleeding did not occur after the direct application of all-in-one adhesives. From this result, all-in-one adhesives are advantageous in direct pulp capping compared with other multi-step adhesives.

Numerous concerns should be pointed out while evaluating the results of direct pulp capping. For instance, there is little correlation between the results of non-human and human studies because of the differences in pulp healing capacities. The effect of direct pulp capping on pulp that was affected by caries in clinical condition cannot be extrapolated from the effects on sound pulp tissue. Moreover, the formation of the hard tissue between the capping materials and pulp has been a controversial issue because it could be produced by either pulpal healing or a reaction to irritation. Therefore, within the limitations of the results of the present study and allowing for DBF as a pulpal healing, the pulpal healing ability of all-in-one adhesives was inferior to that of the control material when they were used as a direct pulp capping material on rat teeth. 


\section{REFERENCES}

1) Hayashi M, Fujitani M, Yamaki C, Momoi Y. Ways of enhancing pulp preservation by stepwise excavation -A systematic review. J Dent 2011; 39: 95-107.

2) Brännström M, Nyborg H. Pulpal reaction to composite resin restorations. J Prosthet Dent 1972; 27: 181-189.

3) Cox CF. Biocompatibility of dental materials in the absence of bacterial infection. Oper Dent 1987; 12: 146-152.

4) Cox CF, Keall CL, Keall HJ. Biocompatibility of surface sealed dental materials against exposed pulp. J Prosthet Dent 1987; 57: 1-8.

5) Cox CF, Hafez AA, Akimoto N, Otsuki M, Suzuki S, Tarim B. Biocompatibility of primer, adhesive and resin composite systems on non-exposed and exposed pulps of non-human primate teeth. Am J Dent 1998; 10: S55-S63.

6) Akimoto N, Momoi Y, Kohno A, Suzuki S, Otsuki M, Suzuki S, CoxCF. Biocompatibility of Clearfil Liner Bond 2 and Clearfil AP-X system on non-exposed and exposed primate teeth. Quintessence Int 1998; 29: 177-188.

7) Kitasako Y, Inokoshi S, Tagami J. Effects of direct resin pulp capping techniques on short-term response of mechanically exposed pulps. J Dent 1999; 25: 257-263.

8) Medina VO 3rd, Shinkai K, Shirono M, Tanaka N, Katoh Y. Histopathologic study on pulp response to single-bottle and self-etching adhesive systems. Oper Dent 2002; 27: 330-342.

9) Hanks CT, Strawn RR, Wataha JC, Craig RG. Cytotoxic effects of resin components on cultured mammalian fibroblasts. J Dent Res 1991; 70: 1450-1455.

10) Hanks CT, Wataha JC, Parsell RR, Strawn SE. Delineation of cytotoxic concentration of two dentin bonding agents in vitro. J Endod 1992; 18: 589-596.

11) Costa CAS, Vaerten MA, Edwards CA, Hanks CT. Cytotoxicity of current dental adhesive systems on immortalized odontoblast cell line MDPC-23. Dent Mater 1999; 15: 434441.

12) Jontell M, Hanks CT, Bratel J, Bergenholtz G. Effects of unpolymerized resin components on the function of accessory cells derived from the rat incisor pulp. J Dent Res 1995; 74: 1162-1167.

13) Becher R, Kopperud HM, Al RH, Samuelsen JT, Morisbak E, Dahlman HJ, Lilleaas EM, Dahl JE. Pattern of cell death after in vitro exposure to GDMA, TEGDMA, HEMA and two compomer extracts. Dent Mater 2006; 22: 630-640.

14) Cui C, Zhou X, Chen X, Fan M, Bian Z, Chen Z. The adverse effect of self-etching adhesive systems on dental pulp after direct pulp capping. Quintessence Int 2009; 40: 26-34.

15) Costa CAS, Hebling J, Hanks CT. Current status of pulp capping with dentin adhesive systems: a review. Dent Mater 2000; 16: 188-197.

16) Inoue S, Vargas MA, Abe $Y$, Yoshida $Y$, Lambrechts $P$, Vanherle G, Sano H, Van Meerbeek B. Microtensile bond strength of eleven contemporary adhesives to dentin. J Adhes Dent 2001; 3: 237-245.

17) Atash R, Van den Abbeele A. Bond strengths of eight contemporary adhesives to enamel and to dentine: an in vitro study on bovine primary teeth. Int J Paediatr Dent 2005; 15: 264-273.

18) Sarr M, Kane AW, Vreven J, Mine A, Van Landuyt KL, Peumans M, Lambrechts P, Van Meerbeek B, De Munck J. Microtensile bond strength and interfacial characterization of 11 contemporary adhesives bonded to bur-cut dentin. Oper Dent 2010; 35: 94-104.

19) Fu J, Kakuda S, Pan F, Hoshika S, Ting S, Fukuoka A, Bao Y, Ikeda T, Nakaoki Y, Selimovic D, Sano H, Sidhu SK. Bonding performance of a newly developed step-less all-in-one system on dentin. Dent Mater J 2013; 32: 203-211.
20) Inoue S, Vargas MA, Abe $Y$, Yoshida $Y$, Lambrechts $P$, Vanherle G, Sano H, Van Meerbeek B. Microtensile bond strength of eleven contemporary adhesives to enamel. Am J Dent 2003; 16: 329-334.

21) De Munck J, Van Meerbeek B, Satoshi I, Vargas M, Yoshida Y, Armstrong S, Lambrechts P, Vanherle G. Microtensile bond strengths of one- and two-step self-etch adhesives to bur cut enamel and dentin. Am J Dent 2003; 16: 414-420.

22) De Munck J, Van Landuyt K, Peumans M, Poitevin A, Lambrechts P, Braem M, Van Meerbeek B. A critical review of the durability of adhesion to tooth tissue: Methods and results. J Dent Res 2005; 84: 118-132.

23) De Munck J, Vargas M, Iracki J, Van Landuyt K, Poitevin A, Lambrechts P, Van Meerbeek B. One-day bonding effectiveness of new self-etch adhesives to bur-cut enamel and dentin. Oper Dent 2005; 30: 39-49.

24) Perdigão J, Geraldeli S. Bonding characteristics of selfetching adhesives to intact versus prepared enamel. J Esthet Restor Dent 2003; 15: 32-42.

25) Ibarra G, Vargas MA, Armstrong SR, Cobb DS. Microtensile bond strength of self-etching adhesives to ground and unground enamel. J Adhes Dent 2002; 4: 115-124.

26) Costa CAS, Hebling J, Garcia-Godoy F, Hanks CT. In vitro cytotoxicity of five glass-ionomer cements. Biomaterials 2003; 24: 3853-3858.

27) Kurata S, Morishita K, Kawase T, Umemoto K. Cytotoxic effects of acrylic acid, methacrylic acid, their corresponding saturated carboxylic acids, HEMA, and hydroquinone on fibroblasts derived from human pulp. Dent Mater J 2012; 31: 219-225.

28) Scarano A, Manzon L, Di Giorgio R, Orsini G, Tripodi D, Piattelli A. Direct capping with four different materials in humans: histological analysis of odontoblast activity. J Endod 2003; 29: 729-734.

29) Silva LA, Freitas AC, Carvalho FK, Queiroz AM, NelsonFilho P, Porto-Neto ST. Direct pulp capping with a selfetching adhesive system: histopathologic evaluation in dogs' teeth. Oral Surg Oral Med Oral Pathol Oral Radiol Endod. 2009; 108: 34-40

30) Koliniotou-Koumpia E, Tziafas D. Pulpal responses following direct pulp capping of healthy dog teeth with dentine adhesive systems. J Dent 2005; 33: 639-647.

31) Costa CAS, Nascimento ABL, Teixeira HM, Fontana UF. Response of human pulps capped with a self-etching adhesive system. Dent Mater 2001; 17: 230-240.

32) Kitasako Y, Inokoshi S, Fujitani, Otsuki M, Tagami J. Shortterm reaction of exposed monkey pulp beneath adhesive resins. Oper Dent 1998; 23: 308-317.

33) Min KS, Park HJ, Lee SK, Park SH, Hong CU, Kim HW, Lee HH, Kim EC. Effect ofate on dentin bridge formation and expression of dentin sialoprotein and hemeoxygenase- 1 in human dental pulp. J Endod 2008; 34: 666-670.

34) Kuratate M, Yoshiba K, Shigetani Y, Yoshiba N, Ohshima H, Okiji T. Immunohistochemical analysis of nestin, osteopontin, and proliferating cells in the reparative process of exposed dental pulp capped with mineral trioxide aggregate. J Endod 2008; 34: 970-974.

35) Tunca YM, Aydin C, Ozen T, Seyrek M, Ulusoy HB, Yildiz O. The effect of mineral trioxide aggregate on the contractility of the rat thoracic aorta. J Endod 2007; 33: 823-826.

36) Costa CAS, Edwards CA, Hanks CT. Cytotoxic effects of cleansing solutions recommended to chemical lavage of pulp exposures. Am J Dent 2001; 14: 25-30.

37) Heggers JP, Stenberg BD, Strock LL, McCauley RL, Herndon DN, Robson MC. Bactericidal and wound healing properties of sodium hypochlorite solutions. J Burn Care Rehabil 1991; 12: $420-424$. 